\title{
Dietary Triggers in Irritable Bowel Syndrome: Is There a Role for Gluten?
}

\author{
Umberto Volta, ${ }^{1}$ Maria Ines Pinto-Sanchez, ${ }^{2}$ Elisa Boschetti, ${ }^{1}$ Giacomo Caio, ${ }^{1,3}$ Roberto De Giorgio, ${ }^{1 *}$ and Elena F Verdu ${ }^{2}$ \\ ${ }^{I}$ Department of Medical and Surgical Sciences, University of Bologna, Bologna, Italy; ${ }^{2}$ Department of Medicine, McMaster University, Farncombe \\ Institute, Hamilton, Ontario, Canada; and ${ }^{3}$ Mucosal Immunology and Biology Research Center, Massachusetts General Hospital, Harvard Medical \\ School, Boston, USA (current address)
}

A tight link exists between dietary factors and irritable bowel syndrome (IBS), one of the most common functional syndromes, characterized by abdominal pain/discomfort, bloating and alternating bowel habits. Amongst the variety of foods potentially evoking "food sensitivity", gluten and other wheat proteins including amylase trypsin inhibitors represent the culprits that recently have drawn the attention of the scientific community. Therefore, a newly emerging condition termed non-celiac gluten sensitivity (NCGS) or nonceliac wheat sensitivity (NCWS) is now well established in the clinical practice. Notably, patients with NCGS/NCWS have symptoms that mimic those present in IBS. The mechanisms by which gluten or other wheat proteins trigger symptoms are poorly understood and the lack of specific biomarkers hampers diagnosis of this condition. The present review aimed at providing an update to physicians and scientists regarding the following main topics: the experimental and clinical evidence on the role of gluten/wheat in IBS; how to diagnose patients with functional symptoms attributable to gluten/wheat sensitivity; the importance of double-blind placebo controlled cross-over trials as confirmatory assays of gluten/wheat sensitivity; and finally, dietary measures for gluten/wheat sensitive patients. The analysis of current evidence proposes that gluten/wheat sensitivity can indeed represent a subset of the broad spectrum of patients with a clinical presentation of IBS.

(J Neurogastroenterol Motil 2016;22:547-557)

Key Words

Biomarkers; Dietary factors; Functional bowel disorder; Gluten; Wheat

\section{Introduction}

Patients with functional bowel disorders (FBDs) manifest variable combinations of intestinal symptoms without structural and/or biochemical abnormalities. The latter concept has been challenged by growing evidence showing low-grade inflammatory changes in the gut and altered gut-brain axis signaling. ${ }^{1,2}$ According to the Rome III classification, FBDs include the irritable bowel syndrome (IBS), functional bloating (FB), functional constipation, functional diarrhea, and unspecified FBD, and they are attributed to abnormalities likely originating from the small bowel, colon, and rectum. ${ }^{3,4}$ Since FBDs lack objective biomarkers, their diagnosis is based on the clinical symptoms reported by patients, physical examination, and the exclusion of alarm symptoms/signs (eg, blood in stools, anemia, weight loss, and others). Although FBDs are not regarded as life threatening, these conditions can significantly worsen the patient's quality of life. Indeed, FBDs are responsible

Received: April 27, 2016 Revised: None Accepted: June 2, 2016

(c) This is an Open Access article distributed under the terms of the Creative Commons Attribution Non-Commercial License (http://creativecommons. org/licenses/by-nc/4.0) which permits unrestricted non-commercial use, distribution, and reproduction in any medium, provided the original work is properly cited.

*Correspondence: Roberto De Giorgio, MD, PhD, AGAF Department of Medical and Surgical Sciences, University of Bologna, St. Orsola-Malpighi Hospital, Building \#5, Via Massarenti, 9-40138 Bologna, Italy Tel: +39-0512143558,Fax: +39-051345864,E-mail: roberto.degiorgio@unibo.it 
for prolonged absenteeism from work as well as for suboptimal performance in the workplace with relevant social costs. ${ }^{5,6}$

Amongst FBDs, IBS is certainly the most common clinical entity affecting up to $20 \%$ of the general population. ${ }^{7}$ Classically, an IBS diagnosis revolves around abdominal pain/discomfort in conjunction with altered bowel habits. The clinical phenotypes include IBS with constipation, with diarrhea (IBS-D), alternating bowel or "mixed" (the most frequent pattern in Western industrialized countries), and unsubtyped according to stool frequency and consistency. ${ }^{3,99}$ The pathogenesis underlying IBS is only partly understood and notoriously referred to as multifactorial being attributable to dysfunction of the gut-brain axis. In this context, recognized mechanisms in IBS span a wide spectrum including gut dysmotility, low-grade inflammation, visceral hypersensitivity, changes of gut microbiome, infections, altered gut barrier function, and genetic and psychosocial factors. ${ }^{10-14}$

The role of dietary factors in IBS pathogenesis is a topic of great interest. ${ }^{15-17}$ Indeed, more than $60 \%$ of patients with IBS relate the occurrence of bloating and abdominal pain to the ingestion of certain foods. The majority of these patients report worsening of symptoms between 15 minutes to a few hours after meal intake. ${ }^{18}$ However, only recent animal and human studies have focused on the key role of specific foods in altering gut physiology.

The aim of the present review is to provide an overview highlighting the major aspects of the complex interplay existing between foods and gut function with relevance to IBS. Specifically, the reader will have an update on the role of gluten/wheat sensitivity as potential dietary triggers evoking gut dysfunction and symptoms in IBS.

\section{Pathogenesis of Irritable Bowel Syndrome}

IBS is a heterogeneous disorder, with multiple clinical presentations and likely different causes. The pathophysiology of IBS is still not well understood, limiting the capacity to effectively treat the disorder. ${ }^{19}$ Enteric infections are the strongest environmental triggers for IBS, constituting the well-characterized subgroup of postinfective IBS, ${ }^{20}$ which is associated with dysbiosis, low-grade inflammation and altered intestinal permeability. ${ }^{21}$ These mechanisms have also been proposed in the general IBS population, but results are not as consistent as in post-infective IBS.2. In addition to enteric infection, other environmental and psychosocial triggers have been linked with IBS. Interestingly, many of these triggers induce visceral hypersensitivity, changes in gut microbiota, and altered levels of enteric hormones and neurotransmitters which may explain symptom generation. ${ }^{19,22,23}$ Alterations in gastrointestinal transit, which may be caused by stress, ${ }^{24}$ have also been reported in IBS patients. Although IBS is considered to affect mainly the colon, several studies have reported motility alterations also in the esophagus, stomach and small intestine, which often correlate with patients' symptoms. ${ }^{25}$

Several studies and a recent meta-analysis ${ }^{26-28}$ have demonstrated bile acid (BA) malabsorption, at least in a sub-population of IBSD. In a study of 119 patients with IBS, ${ }^{28} 32 \%$ had abnormal colonic transit measured by scintigraphy at 24 or 48 hours, with accelerated transit in $48 \%$ of IBS-D patients; the causes of abnormal transit are unclear. BA sequestrants have been proposed as a possible therapeutic option, however, the mechanism of action of these BA sequestrants to ameliorate bowel function is not yet clearly demonstrated. ${ }^{29}$

Of all the possible non-infectious environmental triggers, food is a likely candidate that can affect a variety of physiologic parameters important in IBS such as motility, visceral perception, brain-gut interactions, microbiota composition, permeability, immune activation, and neuro-endocrine function. ${ }^{30}$ Among the foods reported to associate with IBS symptoms, those rich in carbohydrates, ${ }^{19}$ gluten and wheat ${ }^{31,32}$ are common. However, food sensitivity or allergy cannot be always confirmed in patients that recognize a specific food, as a trigger of their symptoms. ${ }^{31}$ Therefore, a better understanding. of the dietary factors involved in IBS and their underlying mechanisms is key to determine the real benefit of exclusion diets in IBS.

\section{Dietary Factors in Irritable Bowel Syndrome -}

Ingestion of a meal activates an array of complex mechanisms enabling the digestive system to perform the complex task of digestion and absorption of nutrients as well as expulsion of waste. Under normal circumstances, our gut has adapted to respond with a tightly regulated system of neuro-immune interactions necessary to maintain proper gut function and homeostasis. Dietary factors, however, can be harmful in certain circumstances and can cause intolerance, allergy, or hypersensitivity via a number of different mechanisms. Food intolerance, such as lactose intolerance, classically relates to a reaction to food components based on some metabolic deficiency. ${ }^{33-35}$ Food allergy and hypersensitivity instead refer to undesirable immune-based reactions that cause symptoms. The most common food sensitivities have been related to proteins in nuts, wheat, and milk. ${ }^{36}$ Some of these reactions are typically IgE mediated (allergy), while others recognize non-IgE immune pathways.

Patients with IBS often report worsening of symptoms by a wheat containing diet. ${ }^{37}$ Gluten is a group of immunogenic proteins in wheat, which causes celiac disease, an inflammatory and autoimmune disease, in genetically susceptible people. ${ }^{38}$ This led to 
the hypothesis that a subgroup of IBS patients could develop mild immune or functional alterations in the absence of celiac disease. ${ }^{39}$ Gluten proteins are indeed insufficiently degraded by gut proteases, leaving undigested peptides that could trigger innate immune mechanisms that may be of importance in IBS. A mouse study determined that gluten sensitization causes altered smooth muscle contractility and altered barrier function, which are mechanisms commonly associated with IBS. It is important to stress that other proteins in wheat, such as $\alpha$-amylase/trypsin inhibitors (ATIs) ${ }^{40}$ and wheat lectin agglutinin, ${ }^{41}$ have recently shown to induce innate immune pathways. ATIs have been shown to trigger a toll-likereceptor (TLR)-4 mediated activation ${ }^{40}$ and it remains to be deter- mined whether this is associated with gut functional changes. In addition to protein fractions, wheat contains a group of carbohydrates, called fructans. These are members of fermentable oligosaccharide, disaccharide, mono-saccharides, and polyols (FODMAPs) that are poorly absorbed in the small intestine. ${ }^{37,40,42}$ These substrates are very important for gut health, supporting microbiota diversity and short chain fatty acid production ${ }^{43}$ but under certain circumstances could cause, through excessive bacterial colonic fermentation, symptoms such as bloating and altered bowel habits. ${ }^{19,44}$ Regardless of the offending component, the withdrawal of wheat from the diet in a subgroup of patients with IBS has indeed been shown to improve symptoms. ${ }^{45}$ Although unselected IBS patients display

Table 1. Evidence for the Effect of Gluten-free Diet in Irritable Bowel Syndrome

\begin{tabular}{|c|c|c|c|c|c|c|}
\hline Author & Study design & Population & Intervention & $\begin{array}{c}\text { Control } \\
\text { diet }\end{array}$ & Outcome & Conclusion \\
\hline $\begin{array}{l}\text { Wahnschaffe } \\
\text { et al, } 2001^{46}\end{array}$ & Observational & $\begin{array}{l}102 \text { IBS-D; } \\
41 \mathrm{CD} \\
30 \text { controls }\end{array}$ & $\begin{array}{l}\text { GFD for } 6 \\
\text { months in } 26 \\
\text { IBS-D }\end{array}$ & - & $\begin{array}{l}\text { Stool frequency; } \\
\text { immune markers } \\
\text { (AGA, tTGA) in } \\
\text { duodenal aspirate; } \\
\text { IELs; HLA-DQ2 } \\
\text { status (in all patients) }\end{array}$ & $\begin{array}{l}\text { Improved stool frequency } \\
\text { and decreased immune } \\
\text { markers in duodenal } \\
\text { aspirates of HLA- } \\
\text { DQ2+ IBS-D patients } \\
\text { after GFD }\end{array}$ \\
\hline $\begin{array}{l}\text { Wahnschaffe } \\
\text { et al, } 2007^{47}\end{array}$ & Observational & $\begin{array}{l}145 \text { IBS-D; } \\
74 \mathrm{CD} \\
57 \mathrm{IBD}\end{array}$ & $\begin{array}{l}\text { GFD for } 6 \\
\text { months in } 41 \\
\text { IBS-D }\end{array}$ & - & $\begin{array}{l}\text { Stool frequency; serum } \\
\text { immune markers } \\
\text { (AGA, tTGA); } \\
\text { HLA-DQ2 status }\end{array}$ & $\begin{array}{l}\text { Improved stool frequency } \\
\text { and decreased immune } \\
\text { markers in HLA- } \\
\text { DQ2+ IBS-D patients } \\
\text { after GFD }\end{array}$ \\
\hline $\begin{array}{l}\text { Biesiekierski } \\
\text { et al, } 2011^{48}\end{array}$ & $\begin{array}{l}\text { DB- } \\
\text { randomized } \\
\text { controlled } \\
\text { trial }\end{array}$ & $\begin{array}{l}34 \text { IBS that } \\
\text { improved on GFD } \\
\text { for } 6 \text { wk; } \\
\text { Marsh } 0 ; 56 \% \\
\text { HLADQ2/8+ }\end{array}$ & $\begin{array}{l}\text { Gluten challenge } \\
\text { (bread/muffin) } \\
16 \mathrm{~g} / \text { day for } \\
6 \mathrm{wk}\end{array}$ & $\begin{array}{l}\text { Gluten-free } \\
\text { muffin/bread }\end{array}$ & $\begin{array}{l}\text { GI symptoms; } \\
\text { intestinal } \\
\text { permeability; fecal } \\
\text { lactoferrin }\end{array}$ & $\begin{array}{l}\text { Gluten triggered gut } \\
\text { symptoms and tiredness } \\
\text { in } 68 \% \text { of IBS patients }\end{array}$ \\
\hline $\begin{array}{l}\text { Sapone et al, } \\
2011^{49}\end{array}$ & Observational & $\begin{array}{l}26 \text { NCGS; } \\
42 \mathrm{CD} ; \\
39 \text { disease controls } \\
\text { (dyspepsia) }\end{array}$ & GFD & - & $\begin{array}{l}\text { GI and extra-intestinal } \\
\text { symptoms; intestinal } \\
\text { permeability }\end{array}$ & $\begin{array}{l}\text { Gluten evoked innate } \\
\text { immune activation in the } \\
\text { absence of changes in } \\
\text { mucosal barrier function }\end{array}$ \\
\hline $\begin{array}{l}\text { Carroccio } \\
\text { et al, } 2013^{50}\end{array}$ & $\begin{array}{l}\text { DB- } \\
\text { randomized } \\
\text { controlled } \\
\text { trial }\end{array}$ & $\begin{array}{l}276 \text { IBS with Marsh } \\
0-1 \text { and negative } \\
\text { skin Prick IgE } \\
\text { that improved with } \\
\text { wheat withdrawal } \\
\text { for } 4 \text { wk }\end{array}$ & $\begin{array}{l}\text { Wheat challenge } \\
\text { (capsules } \\
\text { containing } \\
\text { wheat) for } 2 \mathrm{wk}\end{array}$ & $\begin{array}{l}\text { Placebo } \\
\text { (capsules } \\
\text { containing } \\
\text { xylose) for } 2 \\
\text { wk }\end{array}$ & $\begin{array}{l}\text { GI symptom changes } \\
\text { according to VAS } \\
\text { increase }(>20 \mathrm{~mm})\end{array}$ & $\begin{array}{l}1 / 3 \text { of IBS reacted to } \\
\text { wheat challenge; wheat } \\
\text { sensitive patients had } \\
\text { eosinophil infiltration in } \\
\text { duodenal and colonic } \\
\text { mucosa }\end{array}$ \\
\hline $\begin{array}{l}\text { Biesiekierski } \\
\text { et al, } 2013^{51}\end{array}$ & $\begin{array}{l}\text { DB-cross-over } \\
\text { challenge }\end{array}$ & $\begin{array}{l}22 \text { IBS that } \\
\text { improved on GFD } \\
\text { for } 6 \text { wks; Marsh } \\
0 ; 56 \% \text { HLA- } \\
\text { DQ2/8+ }\end{array}$ & $\begin{array}{l}\text { 2-wk low- } \\
\text { FODMAPs } \\
\text { period, followed } \\
\text { by high-gluten } \\
\text { (16 g/day); 2-wk } \\
\text { washout. Meals } \\
\text { provided }\end{array}$ & $\begin{array}{l}\text { Low-gluten } \\
\text { (2 g/day) or } \\
\text { (16 g whey } \\
\text { protein/day) } \\
\text { for } 1 \mathrm{wk}\end{array}$ & $\begin{array}{l}\text { GI symptom changes } \\
\text { according to VAS } \\
\text { increase }(>20 \mathrm{~mm})\end{array}$ & $\begin{array}{l}\text { No evidence of specific } \\
\text { or dose-dependent } \\
\text { effects of gluten in IBS } \\
\text { patients on previous low- } \\
\text { FODMAPs diet }\end{array}$ \\
\hline
\end{tabular}


Table 1. Continued

\begin{tabular}{|c|c|c|c|c|c|c|}
\hline Author & Study design & Population & Intervention & $\begin{array}{c}\text { Control } \\
\text { diet }\end{array}$ & Outcome & Conclusion \\
\hline $\begin{array}{l}\text { Vazquez- } \\
\text { Roque et al, } \\
2013^{52}\end{array}$ & $\begin{array}{l}\text { Randomized } \\
\text { controlled } \\
\text { trial }\end{array}$ & $\begin{array}{l}57 \text { IBS-D screened; } \\
45 \text { IBS-D } \\
\text { randomized }(50 \% \\
\text { HLA-DQ2/8+) }\end{array}$ & $\begin{array}{l}23 \text { patients on } \\
\text { GFD for } 4 \mathrm{wk} \\
\text { Meals provided }\end{array}$ & $\begin{array}{l}22 \text { patients on } \\
\text { GCD for } \\
4 \mathrm{wk}\end{array}$ & $\begin{array}{l}\text { GI symptoms and } \\
\text { transit; intestinal } \\
\text { permeability; cytokine } \\
\text { profile; TJ proteins }\end{array}$ & $\begin{array}{l}\text { Gluten alters intestinal } \\
\text { barrier in patients with } \\
\text { in HLA-DQ2/8+ } \\
\text { IBS-D patients }\end{array}$ \\
\hline $\begin{array}{l}\text { Rodrigo et al, } \\
2014^{53}\end{array}$ & Observational & $\begin{array}{l}97 \text { IBS and } \\
\text { fibromyalgia; } 58 \\
\text { Marsh I and } 39 \\
\text { Marsh } 0\end{array}$ & GFD for $1 \mathrm{yr}$ & - & $\begin{array}{l}\text { Fibromyalgia } \\
\text { questionnaire; } \\
\text { health assessment } \\
\text { questionnaire (SF36) }\end{array}$ & $\begin{array}{l}\text { Symptom improvement } \\
\text { in IBS/fibromyalgia } \\
\text { patients after GFD }\end{array}$ \\
\hline $\begin{array}{l}\text { Di Sabatino } \\
\text { et al, } 2015^{54}\end{array}$ & $\begin{array}{l}\text { DB-cross over } \\
\text { challenge }\end{array}$ & $\begin{array}{l}92 \text { with suspected } \\
\text { NCGS/NCWS } \\
\text { responding } \\
\text { to GFD; } 61 \\
\text { randomized }\end{array}$ & $\begin{array}{l}\text { Gluten challenge } \\
\text { (capsules }= \\
4.375 \mathrm{~g} / \text { day) } \\
\text { for } 1 \mathrm{wk} \text {; } 1 \text {-wk } \\
\text { washout }\end{array}$ & $\begin{array}{l}\text { Placebo } \\
\text { (capsules } \\
\text { containing } \\
\text { rice starch) }\end{array}$ & $\begin{array}{l}\text { GI and extraintestinal } \\
\text { symptom changes } \\
\text { according to VAS } \\
\text { increase }\end{array}$ & $\begin{array}{l}\text { Gluten evoked overall } \\
\text { GI and extraintestinal } \\
\text { symptom worsening in } \\
\text { some NCGS patients }\end{array}$ \\
\hline $\begin{array}{l}\text { Zanini et al, } \\
2015^{55}\end{array}$ & $\begin{array}{l}\text { DB-cross-over } \\
\text { challenge }\end{array}$ & $\begin{array}{l}112 \text { with suspected } \\
\text { NCGS/NCWS; } \\
53 \text { enrolled; } 35 \\
\text { actually challenged }\end{array}$ & $\begin{array}{l}\text { Gluten containing } \\
\text { flour for } 10 \text { days; } \\
\text { 2-wk washout }\end{array}$ & $\begin{array}{l}\text { Gluten-free } \\
\text { flour }\end{array}$ & GSRS & $\begin{array}{l}\text { Gluten challenge evoked } \\
\text { symptom recurrence in } \\
1 / 3 \text { of NCGS/NCWS } \\
\text { patients }\end{array}$ \\
\hline $\begin{array}{l}\text { Elli et al, } \\
2016^{56}\end{array}$ & $\begin{array}{l}\text { DB-cross-over } \\
\text { challenge }\end{array}$ & $\begin{array}{l}140 \text { FGIDs; } 101 \\
\text { responding to } \\
\text { GFD; } 98 \text { actually } \\
\text { enrolled and } \\
\text { randomized }\end{array}$ & $\begin{array}{l}\text { Gluten challenge } \\
\text { (capsules }=5.6 \\
\mathrm{~g} / \text { day) for } 1 \mathrm{wk}\end{array}$ & $\begin{array}{l}\text { Placebo } \\
\text { (capsules } \\
\text { containing } \\
\text { rice starch) }\end{array}$ & $\begin{array}{l}\text { GI symptom changes } \\
\text { according to VAS } \\
\text { increase }(>3 \mathrm{~cm}) ; \\
\text { SF36 }\end{array}$ & $\begin{array}{l}\text { Gluten challenge } \\
\text { triggered symptom } \\
\text { recurrence in } 14 \% \text { of } \\
\text { patients with FGIDs }\end{array}$ \\
\hline
\end{tabular}

IBS-D, diarrhea predominant irritable bowel syndrome; CD, celiac disease; GFD, gluten-free diet; AGA, anti-gliadin antibodies; tTGA, tissue transglutaminase antibodies; IELs, intra-epithelial lymphocytes; HLA, human leukocyte antigen; IBD, inflammatory bowel disease; DB, double blind; GI, gastrointestinal; NCGS, non-celiac gluten sensitivity; IBS, irritable bowel syndrome; IgE, immunoglobulin E; VAS, visual analogue scale; FODMAPs, fermentable oligo-, di-, and monosaccharides and polyols; GCD, gluten containing diet; TJ, tight junction; SF36, Short Form (36-item) questions health survey; NCWS, non-celiac wheat sensitivity; GSRS, gastrointestinal symptom rating scale; FGIDs, functional gastrointestinal disorders.

clinical improvement after wheat withdrawal, only a proportion may truly reflect underlying gluten sensitivity (Table 1). ${ }^{46-56}$ The absence of specific biomarkers and the great proportion of patients with placebo effect observed in IBS trials, are 2 barriers for identifying the specific role of wheat components in generating IBS symptoms. Therefore, double-blind-placebo-controlled-crossover (DBPCC) trials are a reliable way to establish whether wheat and its fractions are involved in IBS symptom induction. .0,51,53,56 $^{-1}$

\section{Experimental Evidence for a Role of Wheat Components in Irritable Bowel Syndrome}

Different mechanisms have been proposed to explain how gluten may trigger gastrointestinal symptoms in the absence of celiac disease (Figure). In vitro studies have demonstrated that digests of gliadin increase the expression of co-stimulatory molecules and the production of proinflammatory cytokines in monocytes and

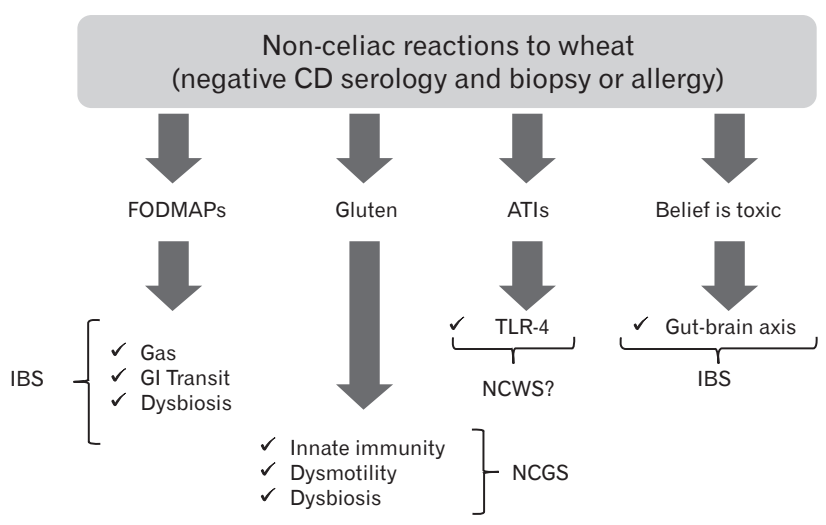

Figure. Putative mechanisms for symptom generation by wheat components. CD, celiac disease; FODMAPs, fermentable oligo-, di-, and mono-saccharides and polyols; ATIs, $\alpha$-amylase/trypsin inhibitors; IBS, irritable bowel syndrome; GI, gastrointestinal; TLR-4, toll-likereceptor-4; NCWS, non-celiac wheat sensitivity; NCGS, non-celiac gluten sensitivity. 
dendritic cells. ${ }^{40,57,58}$ Certain "toxic" (that only stimulates the innate immune response) gliadin-derived peptides such as the 31-43mer, may evoke epithelial cell dysfunction, increased IL-15 production and enterocyte apoptosis. ${ }^{59}$ Recent studies have demonstrated increased expression of TLR-2 in the intestinal mucosa of non-celiac compared to celiac patients, suggesting a role of the innate immune system in the pathogenesis of non-celiac reactions to gluten or other wheat components. ${ }^{49}$ Other studies have shown that monocytes from HLA-DQ2 + non-celiac individuals spontaneously release 2-3 fold more IL-8 than monocytes from HLA-DQ2 negative patients. This suggests that patients without celiac disease (no enteropathy and negative specific serology), but with positive HLA-DQ2 status, may represent a subpopulation reacting mildly to gluten. ${ }^{60}$ In terms of gut dysfunction, gluten sensitization in mice has been shown to induce acetylcholine release, one of the main excitatory neurotransmitters in the gut, from the myenteric plexus. ${ }^{57}$ This correlates with increased smooth muscle contractility and a hypersecretory status with increased ion transport and water movements. ${ }^{57}$ These functional effects induced by gluten were not accompanied by mucosal atrophy, and were not observed after sensitization with non-gluten proteins. Interestingly gluten-induced gut dysfunction was particularly notable in mice transgenic for the human celiac gene HLA-DQ8. ${ }^{57}$

ATIs, a group of wheat proteins that confer resistance of the grain to pests, are strong inducers of innate immune responses via TLR4 and via the myeloid differentiation factor 88-dependent and -independent pathway. ${ }^{40}$ This activation occurs both in vitro and in vivo after oral ingestion of purified ATIs or gluten, while gluten-free cereals display no or minimal activities. ${ }^{61}$ The role of ATIs in IBS is not yet known, however there is clear description of a mechanism that could be involved in the generation of gut dysfunction and symptoms. These mechanisms are different from those proposed for gluten and thus it is conceivable that they could co-exist in given patients or have a synergistic effect.

\section{Clinical Evidence for a Role of Wheat Components in Irritable Bowel Syndrome}

IBS and celiac disease are common conditions, and they may overlap by chance. However, celiac disease is 3-4 times more common in IBS patients compared to controls suggesting that both disorders could be mechanistically associated. ${ }^{62}$ Active screening by celiac serology and biopsy reveals that $4 \%$ of patients labeled as IBS have underlying celiac disease. ${ }^{62-65}$ This overlap between the 2 conditions is different from the issue of wheat components, including gluten, causing functional symptoms in patients without celiac disease. ${ }^{39}$ Clinical studies have revealed that a subgroup of IBS patients in whom celiac disease and wheat allergy were ruled out, displayed intestinal and extra-intestinal symptoms after wheat ingestion. Three consensus conferences defined this new syndrome as nonceliac gluten sensitivity (NCGS) or, alternatively, non-celiac wheat sensitivity (NCWS) given the possibility for immune reactions or intolerances to other wheat components as explained above. ${ }^{66-68}$ It is important to bear in mind the complexity of food hypersensitivities and intolerances, many of which could coexist in the same patient. This constitutes a confounder that we must be aware of for the design and interpretation of clinical trials. ${ }^{69}$

The prevalence of NCGS/NCWS is still not clearly established mainly due to the hitch in standardizing international diagnostic criteria. In United States this condition seems to be identified more frequently in tertiary referral centers than in primary care. Data obtained in primary care practice, from the National Health and $\mathrm{Nu}-$ trition Examination Survey (NHANES), indicate that the estimated prevalence of NCGS/NCWS was $0.6 \%$ over 7762 subjects. ${ }^{70}$ On the other hand, data published from the Celiac Disease Center in Baltimore (University of Maryland), showed a prevalence of suspected NCGS/NCWS of $6 \%$ over 5896 subjects. ${ }^{66}$ Moreover, an Italian multicenter study prospectively evaluated the prevalence of NCGS/NCWS and celiac disease in pediatric and adult centers for gluten related disorders. ${ }^{71}$ Among 12255 subjects consecutively investigated during a one-year survey, 391 (3.2\%) cases of suspected NCGS/NCWS and 340 (2.8\%) celiac patients were identified. Based on these results, it is possible to estimate a ratio between NCGS/NCWS and celiac disease of 1.15:1, data in line with the NHANES survey. Although NCGS/NCWS can occur at any age, this condition seems to occur more frequently in adulthood with a mean age at diagnosis of 40 years. The female gender, similarly to IBS, is more affected by this sensitivity with a ratio up to $5: 1 .^{71}$

Some clinical trials have attempted to investigate underlying functional and immune abnormalities in patients with a clinical picture of NCGS/NCWS. Initial results showed that there is increased expression of TLR2 in the small intestine of patients with NCGS/ NCWS. ${ }^{49}$ This was in contrast with the normal expression of IL17A, IL-6, IFN- $\gamma$, IL-17, and IL-21 in the duodenal mucosa of these patients, which seemed to rule out the contribution of adaptive immunity. ${ }^{72}$ Recent work has suggested increased IFN- $\gamma$ levels in small intestinal biopsies of NCGS/NCWS patients following a short-term gluten challenge. ${ }^{73}$ Although this cytokine is a key mediator of T-helper 1 adaptive immune responses, it could also be produced by innate cells such as intraepithelial lymphocytes (IELs). ${ }^{73}$ 
Table 2. Clinical Trials on Gluten Challenge or Gluten-free Diet in Patients with Irritable Bowel Syndrome

\begin{tabular}{|c|c|}
\hline Supportive & Not supportive \\
\hline $\begin{array}{l}\text { Gluten challenge causes symptoms in IBS } \\
\text { Biesiekierski et al, } 2011^{48} \\
\text { Di Sabatino et al, } 2015^{54 a} \\
\text { Zanini et al, } 2015^{55 \mathrm{a}} \\
\text { Elli et al, } 2016^{56} \\
\text { IBS + celiac genes respond to GFD } \\
\text { Wahnschaffe et al, } 2007^{47} \\
\text { Vazquez-Roque et al, } 2013^{52} \\
\text { Wheat challenge triggers symptoms in IBS } \\
\text { Carroccio et al, } 2012^{50}\end{array}$ & $\begin{array}{l}\text { No dose response to low/high gluten in IBS } \\
\text { Biesikierski et al, } 2013^{51}\end{array}$ \\
\hline
\end{tabular}

${ }^{a}$ Studies performed in non-celiac gluten sensitivity/non-celiac wheat sensitivity patients. IBS, irritable bowel syndrome; GFD, gluten-free diet.

Table 3. Systematic Reviews and Meta-analysis on the Effect of FODMAPs in Patients with Irritable Bowel Syndrome

\begin{tabular}{lccc}
\hline \multicolumn{1}{c}{ Author } & $\begin{array}{c}\text { Clear eligibility } \\
\text { criteria }\end{array}$ & $\begin{array}{c}\text { RCTs } \\
\text { eligible }\end{array}$ & $\begin{array}{c}\text { Meta-analysis } \\
\text { performed }\end{array}$ \\
\hline Moayyedi et al, 2015 $25^{76}$ & Yes & 1 & Not possible \\
Rao et al, 2015 $5^{75}$ & Yes & 4 & Not possible \\
Marsh et al, 2015 2017 & No & 6 & Conducted \\
\hline
\end{tabular}

FODMAPs, fermentable oligo-, di-, and mono-saccharides and polyols; RCTs, randomized controlled trials.

Another relevant pathogenic aspect that has been investigated in NCGS/NCWS pertains to possible functional changes, such as the increase of intestinal permeability. Using the lactulose/mannitol test, IBS patients with self-reported sensitivity to gluten did not exhibit significant alterations in sugar permeability. ${ }^{49}$ This may be related to the population involved or technical difficulties in the interpretation of clinical permeability tests. However, in contrast to this study, Vazquez-Roque et al, ${ }^{52}$ using the same method, found increased intestinal permeability in a subgroup of HLA-DQ2/DQ8 + NCGS/ NCWS patients with IBS-D, once again raising the possibility of a particularly vulnerable subpopulation. This underscores the importance of careful patient phenotyping in studies involving functional symptoms and adverse reactions to food components. It also raises the concept of a subgroup of genetically predisposed individuals carrying celiac markers, but without active celiac disease, that may be more sensitive to low-grade inflammation or functional changes induced by gluten. This will need to be confirmed in large clinical trials.

An initial study enrolling IBS patients fulfilling criteria for NCGS/NCWS showed symptom recurrence following gluten reintroduction. ${ }^{48}$ In a second trial from the same group, ${ }^{51}$ IBS patients that responded to a gluten-free diet were challenged with low dose of gluten ( $2 \mathrm{~g} /$ day), high dose of gluten ( $16 \mathrm{~g} /$ day) or whey protein (16 g/day) after 2 weeks of low dose FODMAPs diet. After the challenge, gluten evoked neurological, but not intestinal, symptoms. It is worthwhile to note that patients increased their symptoms with all challenges, including placebo, and that gluten challenge did not show a dose response. Carroccio et al ${ }^{50}$ demonstrated that IBS patients randomized to receive whole wheat vs placebo, had a significant worsening of their intestinal and extra-intestinal symptoms after wheat ingestion. A recent DBPCC trial used pure gluten vs rice starch (control)-containing capsules to clarify the exact role played by gluten in symptom generation in patients with highly suspected NCGS/NCWS. ${ }^{54}$ The results showed that pure gluten ingestion induced recurrence of a variety of symptoms including, bloating, abdominal pain, foggy mind, aphthous stomatitis, headache and depression, but not in all of NCGS patients. Two recent DBPCC trials $^{55,56}$ performed in IBS patients self-diagnosed as "gluten/wheat sensitive" strongly suggested that gluten/wheat was responsible for symptom generation in up to one-third of IBS patients. Overall the results indicated that gluten and other wheat proteins cause symptoms in the absence of celiac disease in a subset of the IBS population (Table 2).

The dilemma is that a gluten-free diet may also be low in FODMAPs. Some studies have assessed the efficacy of lowFODMAPs diet in IBS with variable results (Table 3). However, none of these trials included a placebo group, thus introducing a possible bias hampering the actual value of a low-FODMAPs diet both in terms of diagnosis and as a therapeutic intervention. A recent DBPC trial (without crossover) comparing a low-FODMAP diet with traditional dietary advice in IBS, showed no difference among the 2 strategies, thus renewing controversy of the specificity 
of therapeutic effect of FODMAPs exclusion in the general IBS population. ${ }^{74}$ Moreover, this study indicated that patients are more likely to react positively to FODMAPs restriction, when already reducing FODMAPs from their diet before initiation of the trial. Finally, the data on the effect of FODMAPs in IBS were pooled in three systematic reviews, and one of them included a meta-analysis. In the systematic reviews from Rao et $\mathrm{al}^{75}$ and Moayyedi et $\mathrm{al}^{76}$ the authors showed that the data could not be combined for metaanalysis and concluded that low-FODMAPs is of uncertain benefit in IBS. In a third review, ${ }^{77}$ with less rigorous inclusion criteria, the authors were able to pool the data and found that low FODMAP diet was effective in IBS. However, the results from this metaanalysis should be taken cautiously due to a great heterogeneity in population included and the comparator for the intervention (Table 3).

\section{Can We Diagnose Non-celiac Reactions to Wheat/Gluten?}

NCGS/NCWS is often considered a self-diagnosis, usually reported by the patient. For the physician, it is based on the thorough evaluation of the clinical features according to the indications proposed by the Consensus Conferences on this syndrome. ${ }^{66-68}$ Identification of biomarkers that allow us to diagnose NCGS/NCWS with more specificity and differentiate it from the unselected IBS population will be key to define and manage this condition. ${ }^{78,79}$

The clinical picture of patients with NCGS/NCWS is characterized by symptoms occurring shortly after consumption of wheat/ gluten containing meals and disappearing or recurring in a few hours/days after specific withdrawal or challenge. ${ }^{66-68}$ Symptoms that characterize IBS, such as bloating, abdominal discomfort/pain, altered bowel habits and tiredness, are present in NCGS/NCWS. It has been suggested that a clinical distinction can be made between general IBS and NCGS/NCWS because of more extra-intestinal manifestations involving the central and/or peripheral nervous system, joint/muscle ("fibromyalgia-like") and skin manifestations in the latter. ${ }^{71}$ Due to the lack of biomarkers, the diagnosis of NCGS/ NCWS remains highly presumptive being based only on clinical and exclusion criteria. ${ }^{80,81}$ The improvement of symptoms after a gluten-free diet, which is regarded as the major diagnostic criteria for NCGS/NCWS, might be due to a placebo effect which often follows the elimination of some foods from the diet. ${ }^{82,83}$ In this context it is important to stress the negative potential influence ("nocebo" effect) generated by media on the "deleterious effect of wheat consumption". There is no scientific evidence to support that gluten/ wheat consumption is deleterious to the overall population and such sensitivity seems to be limited to a subpopulation of patients that present with IBS symptoms. Despite some disproportionate press on one hand, and some healthy skepticism on the other, there is no doubt that awareness and interest in NCGS/NCWS continues to grow. A specific diagnosis requires the development of a biomarker. Antibodies to native gliadin (AGA) have been suggested as a potential diagnostic marker for NCGS/NCWS diagnosis, in the absence of specific celiac serology such as tissue transglutaminase, endomysial and deamidated gliadin antibodies. ${ }^{84}$ AGA have been detected in the sera of about half of NCGS/NCWS patients being predominantly of the IgG class. Although AGA are not specific for NCGS/NCWS being detectable in various conditions, ie, autoimmune disorders, connective tissue diseases and even in healthy controls, their positivity, especially at high titers, in patients with a clinical picture suggestive of gluten/wheat sensitivity may be regarded as a diagnostic adjunct. In parallel to symptom resolution, AGA normalized in almost all patients with NCGS/NCWS within 6 months of gluten-free diet. ${ }^{85}$

In cases with suspected NCGS/NCWS, the most important clinical issue is to rule out celiac disease while the patient is on a gluten-containing diet. Patients with NCGS/NCWS have normal duodenal mucosal histology, although an increased number of IELs ranging from 25 to 40/100 epithelial cells are found in at least 40\% of cases, suggesting an accompanying low-grade inflammation. ${ }^{71}$ There is no increase of T-cell receptor $\gamma / \delta$ IELs in biopsies of patients with NCGS/NCWS. Data on HLA complex and NCGS/ NCWS are unclear. Some studies found that HLA-DQ2 and/or HLA-DQ8 genes were present in $~ 50 \%$ of NCGS/NCWS patients, which is slightly higher than in the general population. ${ }^{84} \mathrm{On}$ the other hand, some studies have suggested that IBS patients who carry celiac susceptibility genes are more likely to respond to the gluten-free diet. ${ }^{52}$ This apparent controversy may be explained by the fact that overall the NCGS/NCWS population may be heterogeneous and responsive to multiple stimuli. It could be speculated that those with celiac susceptibility genes may be more prone to develop mild immune responses and gut dysfunction to gluten. Up to $20 \%$ of NCGS/NCWS show mild laboratory abnormalities, such as low levels of ferritin, folic acid, vitamin D and B12, most likely related to a minimal inflammatory state in the intestinal mucosa. ${ }^{86}$ Evidence of osteopenia detected by bone densitometry has been found in about $50 \%$ of NCGS/NCWS. ${ }^{87}$ Finally, recent data reported a high prevalence of serum autoantibodies (antinuclear antibodies, ANA) and a frequent association with autoimmune disorders (ie, Hashimoto's thyroiditis) in patients with NCGS/NCWS ${ }^{88,89}$ 


\section{Dietary Options in Irritable Bowel Syndrome}

The gluten-free diet as a treatment for celiac disease is well established. No specific guidelines are yet available for the treatment of IBS patients with NCGS/NCWS. Gluten is a common ingredient of many food items and its complete removal is almost impossible to achieve. Exposure to as little as 10-50 mg of gluten (a breadcrumb) can cause intestinal lesions and symptoms in celiac patients, although the threshold for gluten tolerance is unknown in the NCGS/NCWS population. Moreover, there seems to be an individual level of tolerance in NCGS/NCWS. ${ }^{66-68}$ Experts in the field recommend that investigations to rule out celiac disease and wheat allergy should be performed in people who consider themselves as gluten/wheat sensitive before starting a gluten-free diet. ${ }^{66}$

Patients should be warned that an inappropriate dietary restriction can cause nutritional deficiencies. Because gluten-rich grains are important sources of nutrients in the general diet, their exclusion could potentially have major effects on nutritional status. Lower caloric ${ }^{90-93}$ and fiber intake, ${ }^{90}$ but a higher intake of total and saturated fat ${ }^{91,92}$ was observed in the diet of celiac patients compared to healthy control subjects on a gluten containing diet. Lower levels of folate, niacin, vitamin B12, vitamin E, vitamin A, phosphorus, calcium, zinc, and selenium were described in the diet of celiac individuals compared to control subjects. ${ }^{90-93}$ Currently, it is still difficult to draw a conclusion on the nutritional adequacy of a gluten-free diet because of discordant results noticed from the studies regarding macro- and micro-nutrient intake. However, the evidence suggests that following a gluten-free diet may be detrimental if not properly evaluated and medically indicated.

Dietary restriction has been shown to affect the richness and composition of small intestinal and fecal microbiota, reducing beneficial bacterial groups such as Firmicutes. ${ }^{94,95}$ It is necessary to consider that after any restriction diet, adaptations in gut physiology and microbial metabolism could increase sensitivity to the subsequent re-introduction of gluten/wheat or FODMAPs.

The persistence of symptoms after a period of gluten-free diet (at least 6 weeks) in patients with suspected NCGS/NCWS suggests that other food sensitivities/intolerances may be responsible for symptom generation. ${ }^{37}$ In this respect, the patient may benefit from a low-FODMAPs trial excluding rapidly absorbable carbohydrates such as those naturally contained in legumes, onions, honey, pears, water melon, dry fruits, fennel, and dairy products.

\section{Conclusions}

Foods can be triggers of gastrointestinal and extra-intestinal symptoms in a proportion of IBS patients. Inside the spectrum of the so-called food hypersensitivity, NCGS/NCWS has been recognized as a newly identified gluten-related disorder which presents clinically with overlapping symptoms of IBS. ${ }^{66-68}$ Along with gluten, other wheat and food components, have emerged as functional digestive symptom triggers. Within wheat, a potential culprit of symptom generation is ATI, a still poorly investigated soluble protein fraction of wheat. ${ }^{40} \mathrm{~A}$ role for FODMAPs, detectable not only in gluten-containing cereals (wheat, rye, and barley), but also in milk, honey, and legumes, has been proposed, although a recent $\mathrm{DBPC}$ trial did not find this restriction more efficient than traditional dietary advice for IBS patients. ${ }^{74}$ We have discussed the evidence for some specific dietary components, such as gluten and other wheat components, to cause functional digestive symptoms and extra-intestinal manifestations matching the current criteria for IBS. As with overall IBS, the mechanisms underlying symptom generation in the subgroup of patients with NCGS/NCWS are still poorly understood. Our review focused on clinical features with the intent to expand current knowledge in this area of gastroenterology. A better understanding of food hypersensitivity and intolerances as well as the development of biomarkers will enable physicians to design tailored dietary approaches to treat patients with food-related functional bowel disorders.

Acknowledgements: We thank Dr Paul Moayedi for scientific discussions and construction of Table 2. M. Ines Pinto-Sanchez received a CIHR-CAG Health Professional Fellowship Award.

Financial support: Elena F Verdu is funded by CIRH MO\#142773 and holds a Canada Research Chair. Roberto De Giorgio is supported by the Ricerca Finalizzata RER2009 (ItaMNGIE) by the Italian Ministry of Public Health; Telethon (Grant GGP15171) and by RFO (Ricerca Fondamentale Orientata) from University of Bologna, Italy.

\section{Conflicts of interest: None.}

Author contributions: Roberto De Giorgio, Umberto Volta, and Elena F Verdu: concept and design of review and critical revision of the manuscript for important intellectual content; and Maria Ines Pinto-Sanchez, Elisa Boschetti, Giacomo Caio, Umberto Volta, Roberto De Giorgio, and Elena F Verdu: writing of manuscript. 


\section{References}

1. Malagelada C, Drozdzal M, Seguí S, et al. Classification of functional bowel disorders by objective physiological criteria based on endoluminal image analysis. Am J Physiol Gastrointest Liver Physiol 2015;309:G413G419.

2. Ke J, Qi R, Liu C, et al. Abnormal regional homogeneity in patients with irritable bowel syndrome: a resting-state functional MRI study. Neurogastroenterol Motil 2015;27:1796-1803.

3. Longstreth GF, Thompson WG, Chey WD, Houghton LA, Mearin F, Spiller RC. Functional bowel disorders. Gastroenterology 2006;130: 1480-1491.

4. Drossman DA. The functional gastrointestinal disorders and the Rome III process. Gastroenterology 2006;130:1377-1390.

5. Simrén M, Svedlund J, Posserud I, Björnsson ES, Abrahamsson H. Health-related quality of life in patients attending a gastroenterology outpatient clinic: functional disorders versus organic diseases. Clin Gastroenterol Hepatol 2006;4:187-195.

6. Cogliandro RF, Antonucci A, De Giorgio R, et al. Patient-reported outcomes and gut dysmotility in functional gastrointestinal disorders. Neurogastroenterol Motil 2011;23:1084-1091.

7. Lovell RM, Ford AC. Global prevalence of and risk factors for irritable bowel syndrome: a meta-analysis. Clin Gastroenterol Hepatol 2012;10:712-721, e4.

8. Hungin AP, Whorwell PJ, Tack J, Mearin F. The prevalence, patterns and impact of irritable bowel syndrome: an international survey of 40,000 subjects. Aliment Pharmacol Ther 2003;17:643-650.

9. Canavan C, West J, Card T. The epidemiology of irritable bowel syndrome. Clin Epidemiol 2014;6:71-80.

10. Ohman L, Simrén M. New insights into the pathogenesis and pathophysiology of irritable bowel syndrome. Dig Liver Dis 2007;39:201-215.

11. Camilleri M. Peripheral mechanisms in irritable bowel syndrome. N Engl J Med 2012;367:1626-1635.

12. Camilleri M, Lasch K, Zhou W. Irritable bowel syndrome: methods, mechanisms, and pathophysiology. The confluence of increased permeability, inflammation, and pain in irritable bowel syndrome. Am J Physiol Gastrointest Liver Physiol 2012;303:G775-G785.

13. Barbara G, Cremon C, Carini G, et al. The immune system in irritable bowel syndrome. J Neurogastroenterol Motil 2011;17:349-359.

14. Pinto-Sanchez MI, Bercik P, Verdu EF. Motility alterations in celiac disease and non-celiac gluten sensitivity. Dig Dis 2015;33:200-207.

15. Burden S. Dietary treatment of irritable bowel syndrome: current evidence and guidelines for future practice. J Hum Nutr Diet 2001;14:231241.

16. Heizer WD, Southern S, McGovern S. The role of diet in symptoms of irritable bowel syndrome in adults: a narrative review. J Am Diet Assoc 2009;109:1204-1214.

17. Hayes PA, Fraher MH, Quigley EM. Irritable bowel syndrome: the role of food in pathogenesis and management. Gastroenterol Hepatol (N Y) 2014;10:164-174.
18. Simrén M, Månsson A, Langkilde AM, et al. Food-related gastrointestinal symptoms in the irritable bowel syndrome. Digestion 2001;63:108115 .

19. Bolino CM, Bercik P. Pathogenic factors involved in the development of irritable bowel syndrome: focus on a microbial role. Infect Dis Clin North Am 2010;24:961-975, ix.

20. Rodríguez LA, Ruigómez A. Increased risk of irritable bowel syndrome after bacterial gastroenteritis: cohort study. BMJ 1999;318:565-566.

21. Spiller RC, Jenkins D, Thornley JP, et al. Increased rectal mucosal enteroendocrine cells, T lymphocytes, and increased gut permeability following acute Campylobacter enteritis and in post-dysenteric irritable bowel syndrome. Gut 2000;47:804-811.

22. Bercik P, Verdu EF, Collins SM. Is irritable bowel syndrome a low-grade inflammatory bowel disease? Gastroenterol Clin North Am 2005;34:235245, vi-vii.

23. Agrawal A, Houghton LA, Lea R, Morris J, Reilly B, Whorwell PJ. Bloating and distention in irritable bowel syndrome: the role of visceral sensation. Gastroenterology 2008;134:1882-1889.

24. Camilleri M, Neri M. Motility disorders and stress. Dig Dis Sci 1989;34:1777-1786

25. McKee DP, Quigley EM. Intestinal motility in irritable bowel syndrome: is IBS a motility disorder? Part 2. Motility of the small bowel, esophagus, stomach, and gall-bladder. Dig Dis Sci 1993;38:1773-1782.

26. Wedlake L, A'Hern R, Russell D, Thomas K, Walters JR, Andreyev HJ. Systematic review: the prevalence of idiopathic bile acid malabsorption as diagnosed by SeHCAT scanning in patients with diarrhea-predominant irritable bowel syndrome. Aliment Pharmacol Ther 2009;30:707-717.

27. Wong BS, Camilleri M, Carlson P, et al. Increased bile acid biosynthesis is associated with irritable bowel syndrome with diarrhea. Clin Gastroenterol Hepatol 2012;10:1009-1015, e3.

28. Camilleri M, McKinzie S, Busciglio I, et al. Prospective study of motor, sensory, psychologic, and autonomic functions in patients with irritable bowel syndrome. Clin Gastroenterol Hepatol 2008;6:772-781.

29. Camilleri M, Acosta A, Busciglio I, et al. Effect of colesevelam on faecal bile acids and bowel functions in diarrhoea-predominant irritable bowel syndrome. Aliment Pharmacol Ther 2015;41:438-448.

30. Chey WD. Food: the main course to wellness and illness in patients with irritable bowel syndrome. Am J Gastroenterol 2016;111:366-371.

31. Ford AC, Vandvik PO. Irritable bowel syndrome: dietary interventions. BMJ Clin Evid 2015;2015. pii:0410

32. Bhat K, Harper A, Gorard DA. Perceived food and drug allergies in functional and organic gastrointestinal disorders. Aliment Pharmacol Ther 2002;16:969-973.

33. Gibson PR. Food intolerance in functional bowel disorders. J Gastroenterol Hepatol 2011;26(suppl 3):128-131.

34. Bischoff SC, Mayer J, Wedemeyer J, et al. Colonoscopic allergen provocation (COLAP): a new diagnostic approach for gastrointestinal food allergy. Gut 1997;40:745-753.

35. Cuomo R, Andreozzi P, Zito FP, Passananti V, De Carlo G, Sarnelli G. Irritable bowel syndrome and food interaction. World J Gastroenterol 2014;20:8837-8845

36. Philpott $\mathrm{H}$, Yu S, Rao S. It's all in the mix: diagnosis and management of 
food intolerance. Clin Gastroenterol Hepatol 2016;14:1221-1222.

37. De Giorgio R, Volta U, Gibson PR. Sensitivity to wheat, gluten and FODMAPs in IBS: facts or fiction? Gut 2016;65:169-178.

38. Ludvigsson JF, Leffler DA, Bai JC, et al. The Oslo definitions for coeliac disease and related terms. Gut 2013;62:43-52.

39. Verdu EF, Armstrong D, Murray JA. Between celiac disease and irritable bowel syndrome: the "no man's land" of gluten sensitivity. Am J Gastroenterol 2009;104:1587-1594.

40. Junker Y, Zeissig S, Kim SJ, et al. Wheat amylase trypsin inhibitors drive intestinal inflammation via activation of toll-like receptor 4. J Exp Med 2012;209:2395-2408.

41. de Punder K, Pruimboom L. The dietary intake of wheat and other cereal grains and their role in inflammation. Nutrients 2013;5:771-787.

42. Gibson PR, Muir JG, Newnham ED. Other dietary confounders: FODMAPS et al. Dig Dis 2015;33:269-276.

43. den Besten G, van Eunen K, Groen AK, Venema K, Reijngoud DJ, Bakker BM. The role of short-chain fatty acids in the interplay between diet, gut microbiota, and host energy metabolism. J Lipid Res 2013;54:23252340.

44. Basilisco G, Marino B, Passerini L, Ogliari C. Abdominal distension after colonic lactulose fermentation recorded by a new extensometer. Neurogastroenterol Motil 2003;15:427-433.

45. Ferch CC, Chey WD. Irritable bowel syndrome and gluten sensitivity without celiac disease: separating the wheat from the chaff. Gastroenterology 2012;142:664-666.

46. Wahnschaffe U, Ullrich R, Riecken EO, Schulzke JD. Celiac diseaselike abnormalities in a subgroup of patients with irritable bowel syndrome. Gastroenterology 2001;121:1329-1338.

47. Wahnschaffe U, Schulzke JD, Zeitz M, Ullrich R. Predictors of clinical response to gluten-free diet in patients diagnosed with diarrhea-predominant irritable bowel syndrome. Clin Gastroenterol Hepatol 2007;5:844850 .

48. Biesiekierski JR, Newnham ED, Irving PM, et al. Gluten causes gastrointestinal symptoms in subjects without celiac disease: a double-blind randomized placebo-controlled trial. Am J Gastroenterol 2011;106:508514.

49. Sapone A, Lammers KM, Casolaro V, et al. Divergence of gut permeability and mucosal immune gene expression in two gluten-associated conditions: celiac disease and gluten sensitivity. BMC Med 2011;9:23.

50. Carroccio A, Mansueto P, D'Alcamo A, Iacono G. Non-celiac wheat sensitivity as an allergic condition: personal experience and narrative review. Am J Gastroenterol 2013;108:1845-1852.

51. Biesiekierski JR, Peters SL, Newnham ED, Rosella O, Muir JG, Gibson PR. No effects of gluten in patients with self-reported non-celiac gluten sensitivity after dietary reduction of fermentable, poorly absorbed, short-chain carbohydrates. Gastroenterology 2013;145:320-328, e1-e3.

52. Vazquez-Roque MI, Camilleri M, Smyrk T, et al. A controlled trial of gluten-free diet in patients with irritable bowel syndrome-diarrhea: effects on bowel frequency and intestinal function. Gastroenterology 2013;144:903-911, e3.

53. Rodrigo L, Blanco I, Bobes J, de Serres FJ. Effect of one year of a gluten-free diet on the clinical evolution of irritable bowel syndrome plus fibromyalgia in patients with associated lymphocytic enteritis: a casecontrol study. Arthritis Res Ther 2014;16:421.

54. Di Sabatino A, Volta U, Salvatore C, et al. Small amounts of gluten in subjects with suspected nonceliac gluten sensitivity: a randomized, double-blind, placebo-controlled, cross-over trial. Clin Gastroenterol Hepatol 2015;13:1604-1612, e3.

55. Zanini B, Baschè R, Ferraresi A, et al. Randomised clinical study: gluten challenge induces symptom recurrence in only a minority of patients who meet clinical criteria for non-coeliac gluten sensitivity. Aliment Pharmacol Ther 2015;42:968-976.

56. Elli L, Tomba C, Branchi F, et al. Evidence for the presence of non-celiac gluten sensitivity in patients with functional gastrointestinal symptoms: results from a multicenter randomized double-blind placebo-controlled gluten challenge. Nutrients 2016;8:84.

57. Verdu EF, Huang X, Natividad J, et al. Gliadin-dependent neuromuscular and epithelial secretory responses in gluten-sensitive HLADQ8 transgenic mice. Am J Physiol Gastrointest Liver Physiol 2008;294:G217-G225.

58. Nikulina M, Habich C, Flohé SB, Scott FW, Kolb H. Wheat gluten causes dendritic cell maturation and chemokine secretion. J Immunol 2004;173:1925-1933.

59. Chirdo FG, Arranz E. Cereal proteins: immunostimulatory and toxic peptides. Valladolid: Omnia Science Monographs 2016;141-156.

60. Cinova J, Palová-Jelínková L, Smythies LE, et al. Gliadin peptides activate blood monocytes from patients with celiac disease. J Clin Immunol 2007;27:201-209.

61. Schuppan D, Zevallos V. Wheat amylase trypsin inhibitors as nutritional activators of innate immunity. Dig Dis 2015;33:260-263.

62. Ford AC, Chey WD, Talley NJ, Malhotra A, Spiegel BM, Moayyedi P. Yield of diagnostic tests for celiac disease in individuals with symptoms suggestive of irritable bowel syndrome: systematic review and metaanalysis. Arch Intern Med 2009;169:651-658.

63. Sanders DS, Carter MJ, Hurlstone DP, et al. Association of adult coeliac disease with irritable bowel syndrome: a case-control study in patients fulfilling ROME II criteria referred to secondary care. Lancet 2001;358:1504-1508.

64. Zuo XL, Li YQ, Li WJ, et al. Alterations of food antigen-specific serum immunoglobulins $\mathrm{G}$ and $\mathrm{E}$ antibodies in patients with irritable bowel syndrome and functional dyspepsia. Clin Exp Allergy 2007;37:823-830.

65. Sainsbury A, Sanders DS, Ford AC. Prevalence of irritable bowel syndrome-type symptoms in patients with celiac disease: a meta-analysis. Clin Gastroenterol Hepatol 2013;11:359-365, e1.

66. Sapone A, Bai JC, Ciacci C, et al. Spectrum of gluten-related disorders: consensus on new nomenclature and classification. BMC Med 2012;10:13.

67. Catassi C, Bai JC, Bonaz B, et al. Non-celiac gluten sensitivity: the new frontier of gluten related disorders. Nutrients 2013;5:3839-3853.

68. Catassi C, Elli L, Bonaz B, et al. Diagnosis of non-celiac gluten sensitivity (NCGS): the salerno experts' criteria. Nutrients 2015;7:4966-4977.

69. Mansueto P, D’Alcamo A, Seidita A, Carroccio A. Food allergy in irritable bowel syndrome: The case of non-celiac wheat sensitivity. World J Gastroenterol 2015;21:7089-7109.

70. DiGiacomo DV, Tennyson CA, Green PH, Demmer RT. Prevalence of 
gluten-free diet adherence among individuals without celiac disease in the USA: results from the Continuous National Health and Nutrition Examination Survey 2009-2010. Scand J Gastroenterol 2013;48:921-925.

71. Volta U, Bardella MT, Calabrò A, Troncone R, Corazza GR. An Italian prospective multicenter survey on patients suspected of having non-celiac gluten sensitivity. BMC Med 2014;12:85.

72. Sapone A, Lammers KM, Mazzarella G, et al. Differential mucosal IL17 expression in two gliadin-induced disorders: gluten sensitivity and the autoimmune enteropathy celiac disease. Int Arch Allergy Immunol 2010;152:75-80

73. Brottveit M, Beitnes AC, Tollefsen S, et al. Mucosal cytokine response after short-term gluten challenge in celiac disease and non-celiac gluten sensitivity. Am J Gastroenterol 2013;108:842-850.

74. Bohn L, Storsrud S, Liljebo T, et al. Diet low in FODMAPs reduces symptoms of irritable bowel syndrome as well as traditional dietary advice: a randomized controlled trial. Gastroenterology 2015;149:1399-1407, e2.

75. Rao SS, Yu S, Fedewa A. Systematic review: dietary fibre and FODMAP-restricted diet in the management of constipation and irritable bowel syndrome. Aliment Pharmacol Ther 2015;41:1256-1270.

76. Moayyedi P, Quigley EM, Lacy BE, et al. The effect of dietary intervention on irritable bowel syndrome: a systematic review. Clin Transl Gastroenterol 2015;6:e107.

77. Marsh A, Eslick EM, Eslick GD. Does a diet low in FODMAPs reduce symptoms associated with functional gastrointestinal disorders? A comprehensive systematic review and meta-analysis. Eur J Nutr 2016;55:897-906.

78. Rostami K, Hogg-Kollars S. A Patient's Journey. Non-coeliac gluten sensitivity. BMJ 2012;345:e7982.

79. Volta U, De Giorgio R. New understanding of gluten sensitivity. Nat Rev Gastroenterol Hepatol 2012;9:295-299.

80. Biesiekierski JR, Newnham ED, Shepherd SJ, Muir JG, Gibson PR. Characterization of adults with a self-diagnosis of nonceliac gluten sensitivity. Nutr Clin Pract 2014;29:504-509.

81. Aziz I, Lewis NR, Hadjivassiliou M, et al. A UK study assessing the population prevalence of self-reported gluten sensitivity and referral characteristics to secondary care. Eur J Gastroenterol Hepatol 2014;26:3339.

82. Suarez FL, Savaiano DA, Levitt MD. A comparison of symptoms after the consumption of milk or lactose-hydrolyzed milk by people with selfreported severe lactose intolerance. N Engl J Med 1995;333:1-4.
83. Di Sabatino A, Corazza GR. Nonceliac gluten sensitivity: sense or sensibility? Ann Intern Med 2012;156:309-311.

84. Volta U, Tovoli F, Cicola R, et al. Serological tests in gluten sensitivity (nonceliac gluten intolerance). J Clin Gastroenterol 2012;46:680-685.

85. Caio G, Volta U, Tovoli F, De Giorgio R. Effect of gluten free diet on immune response to gliadin in patients with non-celiac gluten sensitivity. BMC Gastroenterol 2014;14:26.

86. Molina-Infante J, Santolaria S, Sanders DS, Fernández-Bañares F. Systematic review: noncoeliac gluten sensitivity. Aliment Pharmacol Ther 2015;41:807-820.

87. Carroccio A, Soresi M, D'Alcamo A, et al. Risk of low bone mineral density and low body mass index in patients with non-celiac wheat-sensitivity: a prospective observation study. BMC Med 2014;12:230.

88. Carroccio A, D'Alcamo A, Cavataio F, et al. High proportions of people with nonceliac wheat sensitivity have autoimmune disease or antinuclear antibodies. Gastroenterology 2015;149:596-603, e1.

89. Volta U, Caio G, De Giorgio R. Is autoimmunity more predominant in nonceliac wheat sensitivity than celiac disease? Gastroenterology 2016;150:282.

90. Wild D, Robins GG, Burley VJ, Howdle PD. Evidence of high sugar intake, and low fibre and mineral intake, in the gluten-free diet. Aliment Pharmacol Ther 2010;32:573-581.

91. Kinsey L, Burden ST, Bannerman E. A dietary survey to determine if patients with coeliac disease are meeting current healthy eating guidelines and how their diet compares to that of the British general population. Eur J Clin Nutr 2008;62:1333-1342.

92. Dall'Asta C, Scarlato AP, Galaverna G, Brighenti F, Pellegrini N. Dietary exposure to fumonisins and evaluation of nutrient intake in a group of adult celiac patients on a gluten-free diet. Mol Nutr Food Res 2012;56:632-640.

93. Bardella MT, Fredella C, Prampolini L, Molteni N, Giunta AM, Bianchi PA. Body composition and dietary intakes in adult celiac disease patients consuming a strict gluten-free diet. Am J Clin Nutr 2000;72:937939.

94. De Palma G, Nadal I, Collado MC, Sanz Y. Effects of a gluten-free diet on gut microbiota and immune function in healthy adult human subjects. Br J Nutr 2009;102:1154-1160.

95. Nistal E, Caminero A, Vivas S, et al. Differences in faecal bacteria populations and faecal bacteria metabolism in healthy adults and celiac disease patients. Biochimie 2012;94:1724-1729. 